\title{
O PAPEL DA DRAMATURGIA NA LEITURA DO IMAGINÁRIO CULTUIRAL: REINTERPRETANDO A IDENTIDADE LATINO-AMERICANA DE UM PONTO DE VISTA FRANCÊS *
}

\author{
Geraldo Pontes Jr.**
}

\begin{abstract}
Resumo: Análise de textos interpretativos do imaginário cultural latino-americano, do ensaio ao teatro, avaliando seus borizontes de abordagem, como forma de ponderar a capacidade de o processo criativo da escritura dramatúrgica estabelecer uma interseçāo com a perspectiva de estudos culturais que os ensaios podem representar. Leitura comparativa da colonização mexicana (e, mais amplamente falando, latinoamericana), através dos textos de Octavio Paz (O labirinto da solidão), de Eduardo Subirats (A penúltima visão do paraíso) e do dramaturgo francês Michel Azama (Aztèques).
\end{abstract}

Apesar do boom das poéticas cênicas dos anos 90, como fator de desconstrução do valor central da modernidade do texto teatral, a atualidade de discussão de idéias novas, que alguns

- Recebido para publicação em março de 2002.

- Professor do Departamento de Letras Neolatinas da UERJ. 
exemplos de dramaturgia são capazes de impor, parece fazer com que essa sobreviva enquanto arte a tudo o que depõe contra o texto na era da imagem cênica. Ao se compor um quadro histórico que possa dar ao espectador amplas reflexões sobre uma cultura, a gama de relações que se engendram no teatro, tributárias da epicização (SZONDI, 1983) da ação dramática, se recria, via de regra, na significação do plano discursivo, para dar conta dos diferentes sentidos dos fatos. Uma vez emblemático daquilo que, aos olhos do mundo, remete de maneira polissêmica para aspectos de uma ou várias culturas ou povos, esse quadro histórico, leitura do mundo, funciona tanto melhor quanto mais se potencializa como mediação, para o espectador, de conhecimentos muitas vezes gerais (inconscientes ?) sobre a identidade, porque escondidos no limbo do pragmatismo cotidiano. O distanciamento da arte teatral em relação a esse pragmatismo, seja pelo seu viés literário, seja pelas estratégias da dinâmica do palco, é hoje em dia indissociável da tradição brechtiana, segundo a qual "distanciar é ver em termos históricos"(BRECHT, 1978:37). Atualmente, não mais se lança mão da estética de distanciamento, entretanto, para repetir, pela técnica brechtiana, leituras marxistas, e sim para marcar esse distanciamento, entre outras possibilidades, de um conceito prévio através do qual, por exemplo, o olhar de uma cultura para as outras propõe leituras, inclusive marxistas, dos fatos.

A peça Aztèques, do dramaturgo francês Michel Azama, faz incursões na conquista do México pelos espanhóis, analisando os papéis e as contradições assumidos pelos colonizadores e pelos mártires do episódio. As rubricas que precedem o texto ("a peça se passa em um espaço-tempo onírico" [AZAMA, 1992:10]) pretendem descontextualizar a situação dramática, em vez de datar claramente sua referência histórica, para reescrever os fatos de forma relativizadora através da retórica dramática, dando a tal 
discurso o estatuto de reflexão, e a função de repensar o presente através do passado. A intriga da colonização das Amériças, mais uma vez pretexto para a reflexão cultural, vê-se assim reescrita nesse espaço-tempo onírico aberto à desconstrução.

Caberia citar aqui primeiramente interpretações nãoliterárias sobre a colonização mexicana, sem querer esgotar qualquer discussão, para balizar noções de identidade cultural. Segundo Octavio Paz, em O labirinto da solidão, o massacre dos astecas pelos espanhóis e a conseqüente aniquilação da cultura e religião indígenas gerou no imaginário do mexicano um sentimento de "orfandade". Acreditando-se abandonados pelos deuses e traídos por parte dos guerreiros de seu povo, como Moctezuma, que se rendeu ao conquistador, os mexicanos perderam sua identidade, fechando-se em si mesmos, renegando o passado e, sobretudo, recusando-se a ser índios ou espanhóis, o que os remete a uma solidão secular, dissimulada em atos extremados e festejos estrondosos.

Não é possível entender como se construiu e se perpetuou ao longo de séculos a simbologia do órfão, interiorizada pelo mexicano, sem se chegar à figura de Malinche. A índia que se entrega ao conquistador, e por este é usada, representa, na abordagem de Paz, a "Chingada". Quando, ainda nos dias atuais, os mexicanos gritam nas comemorações da Independência do país: "Viva o México, filhos da Chingada!", estão exorcizando a vergonha pela violação de seu povo. A Chingada é a mãe violada, "aberta", passiva; e seus filhos são os estrangeiros, os maus mexicanos, os inimigos. Daí a expressão "malinchista" contagiado pelas tendências estrangeiras.

No balanço deste conjunto, Octavio Paz também relativiza o sentido da rendição dos grupos astecas aos colonizadores, analisando-a sob o prisma da dualidade de sua religião. Ao se perguntar por que Moctezuma cede, conclui: 
A chegada dos espanhóis foi interpretada por Moctezuma - pelo menos no início - não tanto como um perigo 'externo', mas sim como o acabar interno de uma era cósmica e o princípio de outra. Os deuses vão embora porque seu tempo acabou; mas volta outro tempo e com ele outros deuses, outra era. (PAZ, 1994:87)

Vale ressaltar também que a chegada dos espanhóis significou a liberação para os povos submetidos aos astecas, tendo em vista que estes últimos promoveram a unificação das culturas locais sob o domínio de seu império - teocrata e militar. Em contrapartida, o imperador asteca Cuauhtémoc, torturado e assassinado por Cortés, que lutara sabendo da inevitável derrota, como se caminhasse para o sacrifício final, torna-se um mito para os mexicanos, representando o "jovem avô": "o túmulo do herói é o berço do povo" (PAZ, 1994:78). Ignora-se, entretanto, até hoje, o lugar do seu túmulo, o que impede o mexicano de "voltar à sua origem, reatar sua filiação, romper com a solidão".

Em um quadro mais geral de discussão da colonização latino-americana, Eduardo Subirats entende, com seu ensaio $A$ penúltima visão do paraíso, que a centralidade das estratégias de comunicação e de representação da cultura pós-moderna esconde, hoje em dia, os princípios reais da violência constituinte com que se espoliaram os primeiros índios / nativos e com que se consolidou a aniquilação do imaginário latino-americano: "Nunca existiu um espaço de possíveis negociações simbólicas, nem esferas autônomas de reconhecimento; só a constituição a uma só vez sacramental e militar da massa submissa, escravizada, cristianizada"(SUBIRATS, 2001:109). Genocídio e conversão, instrumentos de negação do outro, pelo colonizador, desdobramse ainda, segundo Subirats, nos efeitos das interpretações contemporâneas da colonização, que não analisam a violência contínua 
das paisagens sociais da América Latina, mas se detêm nas características estéticas de sua representação. Ressalta, da postura eurocêntrica de um Todorov: "A conquista e a destruição de Tenochtitlán por Cortés constituíram, de acordo com sua interpretação, uma performance, um jogo de ícones, um espetáculo" (SUBIRATS, 2001:110) ${ }^{1}$. Considera ainda, segundo outros estudos, que a questão dos espaços simbólicos de troca, pela resistência dos nativos, criou, na mestiçagem, não o seu sentido plural, mas a violência com que o espaço do reprimido se instaura, "em seu processo discursivo, sacramental e institucional de destruição material e de limpeza simbólica, e em seu prolongamento indefinido ao longo da descolonização, da modernização e da pós-modernização da América Latina" (SUBIRATS, 2001:111).

Do quadro contundente de Subirats permanece a questão do híbrido como grande engodo, fruto da própria condição do cristianismo de não ter origem ligada à memória de um povo, o que "se projeta numa expansão global indefinida, que o obrigou, ao longo de sua história, à hibridação de tudo o que pudesse encontrar em seu caminho" (SUBIRATS, 2001:112).

Desses dois primeiros quadros, a leitura de Paz aceita como constituinte da essência dialética e contraditória da nova identidade dos povos descolonizados um impasse que a indefine, tanto no sentido angustiante de manter a busca de seu perfil quanto na possibilidade de a reflexão ajudá-la a ultrapassar esse desejo. Isso traz sua interpretação, possivelmente, a uma perspectiva mais próxima à dos povos nativos, ao renunciarem ciclicamente à preponderância de seu domínio, e estarem abertos à influência alheia. Para Subirats, é preciso retornar às origens, restabelecer o discurso das memórias nativas para derrotar todo

\footnotetext{
' Referências à obra de Todorov, La conquête de l'Amérique. Paris, Seuil, 1982.
} 
projeto da colonização e de sua teologia aniquiladora. No primeiro, a aceitação da dinâmica contraditória de que se alimentam as novas culturas como viabilização de um conjunto heterogêneo e novo; no segundo, tendo como ponto de partida a noção de que a identidade do presente é falsa, cindida, resta a tarefa de se restabelecer uma origem ideal.

Ora, a discussão de Subirats, por estar desprovida de mediação, com um conceito de origem aparentemente utópico, pelo pouco desenvolvido que é, parece recusar a idéia de um coletivo composto pela dinâmica heterogênea das culturas contemporâneas que interagem na relativização da identidade. Estaria aqui a origem atrelada a um conceito de raiz inata, nas populações mestiças, com seus ritos tribais e o desejo - burguês? - de reconstruir uma herança por elas perdida? Por outro lado, uma vez que seu estudo se aplica aos trópicos como um todo, no caso da Revolução Cubana, a mudança do estatuto de cidadania de sua população em relação ao conjunto histórico abordado, de colonização ibérica e cristã, possivelmente demonstraria a não aplicação de seu pensamento, por mais que se possa propor que o conceito de coletivo tampouco se aplica à identidade cubana, como uma crítica ao regime político socialista sobrepor-se à autonomia de seus cidadãos - o que também, nos dias de hoje, já está bem mais relativizado em Cuba, e contradições já chegam a ser apontadas internamente como resultantes do regime.

Se a interpretação relativizadora de um poeta latinoamericano e o descontentamento de um ensaísta europeu quanto ao discurso hegemônico do Velho Mundo divergem em posicionamentos, a dramatização das reflexões históricas sobre o episódio da colonização mexicana como metonímicas de todo o processo latino-americano caracterizam a leitura de um dramaturgo francês. Cotejar a obra Aztèques aos discursos dos ensaístas sobre a História e a identidade latino-americanas possibilita 
entender o que uma obra literária propõe por identidade, como leitura relativizadora de conclusões históricas. Cabe salientar, entretanto, que a ótica do autor francês também revela particularidades que limitam relativizações a seu conceito de cidadania, talvez, com que pretende entender a existência alheia.

Apresentada em três partes (DESCOBRIR - AMAR DESTRUIR), a peça desenvolve os sentidos desses três signos. A inserção de tais termos na abertura dos atos sugere usos em montagens da narratividade brechtiana, com a técnica dos cartazes, inserindo títulos e textos em cena capazes de delimitar a observação. Descobrir identidades cindidas: o Papa e o monge infelizes com a mesmice cristã desprovida de verdadeiro fundo moral; Moctezuma, o imperador cruel que se vê alienado do coletivo; Cortés, o colonizador em busca de uma nova razão de viver. Amar o outro com a crença de ultrapassar relações conflitantes entre mundos distintos e, finalmente destruí-lo para desconstruir as expectativas das personagens sobre seus destinos.

A estrutura não ressalta a sucessão cronológica rígida, como já proposto pela rubrica inicial, mas, entre a entrada e a conquista do colonizador, erige aos poucos o drama das personagens. Um efeito de distanciamento embute-se nas personagens para fazer com que as mesmas atuem, construindo os fatos, e assistam à desconstrução dos mesmos.

O discurso sobre a colonização, sempre presente na fala do espanhol Cortés, do Papa e do monge Bernardino, está baseado na sua função religiosa, fazendo perpassar a negatividade da mesma que unifica os diferentes agentes da colonização, do exército à Igreja. Conotando a um só tempo o mecenato do navegador e o instrumento de genocídio cultural do povo nativo, esse discurso traduz a posição nula de Cortés quanto à alteridade: "[...] A fé é uma arma mais poderosa que as armas humanas, mesmo quando o homem tiver o poder de explodir a 
terra e abri-la em duas ..." (AZAMA, 1992:33). Cortés experimenta todavia, com a missão colonial, o fascínio de ser esperado pela civilização indígena comparando-se ao Cristo, em virtude de o empreendimento colonial ser uma continuidade da expansão da fé cristã pelo mundo. Bernardino contrapõe o projeto geral - cristão - com o subjetivo e individual de Cortés:

Cortés - [...] Então o Cristo não conquistou o mundo desde sua mangedoura de Belém de onde nos deu a missão de acabar essa conquista?

Bernardino - Você quer lutar contra os astecas e eu contra o asteca que vejo nascer em você.

Cortés - Não. Quero conquistar este país pela palavra de Deus e você me ajudará. Tornarei cativo seu imperador e serei seu amigo, farei tudo para que o reino de Deus avance pela ternura.

Bernardino - Eu serei sua consciência.(AZAMA, 1992:34)

Ao opor pontos de vista passíveis de se ler como diferentes ideais cristãos convergentes, essa leitura vai ao encontro da noção de Subirats quanto à fé cristã ser desprovida de origem, irradiadora do imperialismo ocidental, aniquiladora das culturas primitivas. Descobrir para destruir é o que se ressalta da discussão entre o monge Bernardino e o Papa, em que o sentido de amor cristão torna ambígua a palavra da Bíblia, pois é a espada que representa, para o Papa, a mensagem do Cristo: "Não vim trazer a paz, mas a espada!"(AZAMA, 1992:50).

Amar, signo mais próximo de aniquilar, ilustra-se no confronto de culturas que se desenvolve nos diálogos de sedução entre Malinche e Cortés. A relação dos dois personagens passa por comparações de juízo de valor entre a civilização asteca e a ocidental, mas também reflete ambiguamente sobre a apropriação, pela nativa, da língua do colonizador, ponto nodal dos 
dilemas da sedução e de seus desdobramentos no destino de quem faz uma escolha tão conflituosa. Assim, a conversa entre Malinche e Cortés é permeada de antevisões do massacre, misturando-se ao fascínio do envolvimento com o outro:

Malinche - Você me deu uma doença. Minhas duas línguas se embaralham. Sim, uma doença. Como se eu fosse bígama sem saber a quem estou enganando. [...] Você quer me jogar em uma armadilha.

Cortés - Qual armadilha? Só há aquela que escolhemos de cruzarmos nossos destinos. (AZAMA, 1992:50).

A história contada através do jogo amoroso como um ardil, no âmbito individual, desloca o eixo da traição de Malinche para o encontro do acaso, desconstruindo da figura da índia a imagem de bode-expiatório que entregou os segredos de seu povo ao conquistador. À pergunta de Malinche sobre Cortés ser um agente da destruição - elemento de dúvida e hesitação da mulher asteca -, o espanhol responde que os astecas também são destruidores, em uma ótica cristã:

Cortés - A ação torna os excessos necessários. Vim acabar com os sacrifícios. Dar a teu povo a felicidade de ser uma espiga de milho que pode amadurecer tranqüila sob o sol e gozar de sua colheita inteira.

Malinche - A espiga não goza da colheita e sim aquele que a corta e a cozinha para fazer seu pão; e o seu pão não é o milho, e sim o ouro. [...]

Cortés - [...] A Espanha cheira a curtume e a carne defumada, a suor de árabe e a sujeira de judeu, alho e cebola fritos, e muita gente só tem terra pra comer. Mas nós temos o paraíso e não poderíamos thes dar melhor presente. Eis o que vim fazer aqui. 
Malinche - E o que você quer de mim? (AZAMA, 1992:37).

A fala de Cortés hierarquiza, estabelece graus de obediência para desmetaforizar e remetaforizar o paraíso na terra nova. Octavio Paz conta que no imaginário asteca vivia-se o fim de um ciclo de poder e esperava-se a chegada de outro Deus; na peça, Moctezuma, o imperador e feiticeiro a quem não se pode olhar nos olhos, e nem tocar, encarna a divindade que aos poucos se fragiliza, a começar por sua hesitação, quando pergunta ao espectro de seu pai se os que chegaram são os deuses anunciados por suas crenças:

Moctezuma - São eles os deuses de nossas profecias? Como reconhecê-los? [...] A angústia me rasga o coração [...]. Saiba que o senhor não me deu nenhuma resposta clara. Enquanto viveu entre nós, levou a vida feliz de um deus sobre a terra. Diga-me se sou culpado? Esse tempo que virá ainda está longe de nós? (AZAMA, 1992:39).

Desconfiado de que a tarefa dos espanhóis será a destruição de sua cidade, o imperador asteca procura entender se este Outro, vindo de navio, têm as mesmas interrogações a respeito dos astecas e orgulho em conhecê-los. O quadro prepara um impasse que caracteriza o reconhecimento recíproco. E é justamente o encontro que fragiliza o imperador ao colocá-lo diante do primeiro homem que o olhará de frente sem ser punido: "Cortés desce do cavalo e avança sorrindo em direção do grande imperador" (AZAMA, 1992:42). A primeira fala de cada um dos personagens é a mesma ("Ele me olhou bem nos olhos"), em uma construção poética de onde a igualdade de forma se desfaz na diferença de sentido, como mostra a frase final do diálogo: 
Moctezuma - E tudo em seus olhos é tão inexplicavelmente velho quanto o próprio oceano.

Cortés - Há algo impudico no poder destes olhos. (AZAMA, 1992:43).

A divagação de Moctezuma, no sentido de entender a vinda de Cortés, os obstáculos por que passou para chegar até ali, demonstra sua expectativa. A de Cortés é a do explorador e conquistador que, repentinamente, esquece-se do outro e pensa no que quer obter: "Em que província das Índias caímos? Onde estão suas inesgotáveis minas de ouro?" (AZAMA, 1992:43). Finalmente, no diálogo que passa a ser intermediado por Malinche como a tradutora das falas, Moctezuma diz tudo o que o outro representa, declarando que o esperava. Cortés se dissimula em uma simbologia; seu olhar dessacraliza e fragiliza aos poucos Moctezuma, tornando-o mais espectador que actante de seu destino. Faz sua crise de consciência crescer:

Moctezuma - As estrelas nos ensinaram há muito sua vinda. Nossas crianças não herdaram nada de seus pais. Cada um recomeça sua vida no mesmo ponto. Nenhuma estrada está fechada e nem traçada antes para ninguém. Cortés - [...] Viemos na paz do Cristo.

Moctezuma - [...] No olho de cada amigo leio o olhar de um traidor e às vezes o olhar de um amigo no olho de um traidor. [...] E você? Amigo? Inimigo? Traidor? Hipócrita? [...] Então inimigo? Você é o meu duplo. Tão traidor e perjuro e criminoso e culpado quanto eu. Eis porque desde já gosto de você. E desde já o odeio. $\mathrm{E}$ desde jà me é necessário. E desde já receio perdê-lo. [...] É o primeiro que me olha nos olhos, pois qualquer outro estaria condenado à morte...". (AZAMA, 1992:54). 
Assim, a leitura que Michel Azama faz da História relativiza o confronto de posicionamentos que seriam representativos de ideologias em alguns aspectos. Uma vez confrontadas, instaurase na peça uma ambivalência sobre os pontos de vista de cada cultura em jogo. Até o momento do primeiro encontro com Moctezuma, e não antes da morte deste, a fala de Cortés sobrepõe a fé cristã à outra cultura, propondo a redenção que expulsa as trevas e os fantasmas da cultura do outro. Todo discurso de Cortés põe em questão as crenças indígenas e estimula a ilusão para dominar e hierarquizar o instrumento da fé católica como superior: "Eu valho qualquer um dos seus deuses" (AZAMA, 1992:54). O ritual de encontro entre as duas personagens, sacrilégio a que assiste horrorizado o grande sacerdote, conselheiro do imperador, significa a anulação hierárquica dos astecas, pelo fato de Cortés olhá-lo de frente: é o desmonte da cultura asteca e um sinal da perda iminente da guerra. Paradoxalmente, para Moctezuma, isso instaura a sensação do novo. Um novo já esperado.

Quando Cortés cospe o cálice de sangue que Moctezuma the oferece, o sacrilégio reforça a ambivalência do "encontro" porque deixa o imperador hesitante, sem ação, sentindo-se enganado por ter esperado do outro - um deus - o conhecimento de sua cultura. Durante a invasão do palácio, Malinche adverte Moctezuma quanto ao perigo, mas o imperador, cético, descrente de seu destino, apenas questiona as convicções de Cortés, e, provocando-o, também compara-se ao Cristo:

Moctezuma - $[\ldots]$ eles sonham que você me matará e que renascerei de manhã. Para verem que você não pode nada contra mim.

Cortés - São loucos. Se você é um deus porque tem um corpo de homem? 
Moctezuma - "... Morreu sob Pôncio Pilatus e ressuscitou ao terceiro dia..."

Cortés - Quem lhe ensinou?

Moctezuma - Os seus padres apregoam isso toda manhã. Não acredita então que seu deus ressuscitou de seu corpo de homem no terceiro dia? [...] O que pode um deus o outro também.

Cortés - Blasfêmia. Na Espanha isso o levaria à fogueira. Moctezuma - A morte. Só aprenderam a dá-la. Nós aprendemos a recebê-la. Que diz seu rei? Pensa que devo morrer?

Cortés - Não sei, não temos barcos.

Moctezuma - Estranhos deuses que esperam barcos para suas respostas. (AZAMA, 1992:66).

Ao contrastar-se com a esperança da crença indígena pelo novo ciclo, a unilateralidade da fé católica, aniquiladora, também se descentra diante do argumento de Moctezuma segundo o qual ele próprio é a promessa cristã do retorno do filho de deus à terra. Mas ao vislumbrar por fim o engodo da profecia, o guerreiro asteca encara os espanhóis como a poeira dos seus sonhos. Ferido na multidão e, traído por seu povo, é levado pelos espanhóis. Sua morte desencadeia a crise de consciência de Cortés que também morre, chamando por Moctezuma: "Entrei em sua casa e brincamos como duas crianças. Pus a mão sobre seus olhos e disse: adivinhe quem é. E era a morte... [...] Moctezuma! Acorde. Você não está morto. Um deus não sabe morrer". (AZAMA, 1992:71).

A quebra das convicções de Cortés e Moctezuma, representantes centrais das culturas em confronto, tendo como conseqüência o aniquilamento de ambos - o que não segue com fidelidade os fatos reais -, acaba por privilegiar uma abordagem. da História coletiva, uma vez que as personagens que discursarão ao final, em uma perspectiva diacrônica, se redimensio. 
nam como característicos de grupos sociais de homens comuns: Bernardino, o monge idealista do pequeno clero, e Malinche, não mais a traidora, mas o pária da sociedade patriarcal: a mulher, mãe da "nova" civilização bastarda. A leitura do dramaturgo remete aos dois ensaios aqui citados ao se preocupar com figuras simbólicas do coletivo.

Para dar um "sentido inacabado" a sua obra, Azama privilegia, no fecho da intriga, situações anacrônicas colocadas entre os diálogos, que ilustram a vitória espanhola e o massacre dos nativos. A fala de Bernardino introduz elementos futuros para narrar o massacre por fragmentos, criando um efeito segundo o qual contar a história é mudar a perspectiva temporal; como se fosse possível vê-la mais à frente - o massacre histórico sendo a face implícita da identidade do presente. Introduz assim uma reflexão em que o passado está superposto no presente. Da mesma forma, um monólogo final de Malinche, deslocado para o futuro, fala do poder de um único projeto de destruição, o do Ocidente. Grávida do espanhol, ridiculariza o futuro do fruto de seu ventre, resultado da mestiçagem, sendo a aculturação responsável por seu mau resultado.

Malinche - A tragédia da América é assustadora. A América está morta. Carruagens trouxeram o colt e Ford os catálogos de venda por correspondência e a América gerou a bomba atômica. Eis a mão do Deus de vocês.

Meu filho, belo filho da traição... sou maldita entre todas as mulheres e o fruto de minhas entranhas é maldito. (AZAMA, 1992:84).

O sentido de destruir, já desenvolvido no decorrer da dialética apresentada pela peça entre descobrir e amar, cria uma perspectiva interessante ao transfigurar historicamente a sim- 
bologia de Malinche e Bernardino. A arquienunciação do texto teatral ganha efeito ao contar coletivamente a História, quando surgem falas que analisam diferentes aspectos de um quadro já histórico, diacrônico. Um tecido fragmentado em pontos de vista heterogêneos configura o caráter do discurso teatral, entre representação e reflexão cultural. Exalta-se com sarcasmo a atemporalidade da dominação, entre o discurso de Malinche, Moctezuma, do monge, do povo. No caso da índia, o efeito toma uma proporção metafórica, como se a traição da nativa fosse passível de dar sentido ao resultado moderno da aculturação, no "fruto de seu ventre".

Daí se entende a inserção do autor, através de sua ficção ou melhor dizendo, dramatização - na construção de um pensamento sobre a identidade cultural latino-americana, tomando o exemplo mexicano. O fecho da peça é uma cena de total anacronismo, em que, através de uma câmera de tv e projetores, representando o poder de um sistema que contrasta com a fragilidade do embate dramático das personagens sobre o palco, entrevistase o monge Bernardino para saber o que teria sido ao longo dos séculos sua peregrinação sem sentido e sua vida, na busca vã de um novo porto. Ao que o monge apenas responde que foi uma catástrofe gratuita. O "metateatro" deflagra assim o engodo em que todos acreditaram, segundo aquilo em que se empenharam em ser, e aponta, na conseqüência da aculturação, para uma instância maior que os homens impedindo-os de escolher seus destinos.

Balanço negativo: no conjunto da leitura de Azama, assiste-se à destruição da identidade como o drama de Cortés, Malinche, Moctezuma, do jovem monge. Através desse lastro de destruição descrito ao final por Malinche e Bernardino, o dramaturgo relativiza a ação dos homens e os constrói como antiheróis que sucumbem às forças maiores, veiculados por discursos de dominação que querem impor uma identidade cole- 
tiva. Resta indagar se esta seria a sua visão sobre o mundo dos outros, os latino-americanos, e se, assim, seria também aprisionadora como proposta para a construção das "nossas" identidades.

Impregnado talvez pela concepção de cidadania dos povos ditos desenvolvidos, o dramaturgo francês não deixa de propor um distaciamento crítico para dotar o espectador da consciência de súa escolha, com uma visão plural da alteridade, para que se veja como partícipe da História, por mais perigosa e prejudicial que esta possa se apresentar. É necessário destacar o papel do teatro de Michel Azama na reescrita do jogo da existência, da tensão dramática como (ilusão da) crença na vida, na observação ideológica como análise da superposição de discursos fưndadores que confundiram as perspectivas, ao longo do tempo, das jovens nações.

Mas entre diferentes visões de relativização da identidade cultural aqui apresentadas, pergunto-me se a leitura poética de Octavio Paz sobre a consciência mexicana, como de certa forma emblemática do conjunto latino-americano, não estaria, ainda, à frente das outras, na tentativa de propor a quebra dos limites da imaginação, para relativizar as essências, aproximando-se mais assim das perspectivas do imaginário dos nativos, que o próprio projeto crítico ao pós-colonialismo, do retorno às origens, aspirado por Subirats.

Résumé: Analyse de textes interprétatifs de l'imaginaire culturel latino-américain, de l'essai au théâtre, dans une évaluation de leurs horizons d'approche comme mojen de pondérer l'efficace du processus créatif de l'écriture dramaturgique dans l'établissement d'une intersection avec la perspective des études culturelles que les essais peuvent représenter. Lecture comparative de la colonisation mexicaine (et, pour parler plus amplement, latino-américaine) à 
travers les textes, en version brésilienne, d'Octavio Paz $(\mathrm{O}$ labirinto da solidão), d'Eduardo Subirats (A penúltima visão do paraíso) et de l'oeuvre du dramaturge français Michel. Azama (Aztèques).

\section{Referências bibliográficas}

ABIRACHED, Robert. La crise du personnage dans le théâtre moderne. Paris: Gallimard, 1994.

AZAMA, Michel. Aztéques. Paris: Théâtrales, 1992.

AZAMA, Michel. Le sas. Paris: L'Avant-Scène, 1986.

AZAMA, Michel. Vie et mort de Pier Paolo Pasolini. L'Avant-Scène, 1986.

BENTLEY, Eric. O Dramaturgo Como Pensador. Tradução de Ana Zelma Campos. Rio: Civ. Brasileira, 1991.

BRECHT, Bertolt. Estudos sobre o teatro. Trad. de Fiama Paes Brandão. Rio de Janeiro: Nova Fronteira, 1978.

BRADBY, David. Le théâtre français contemporain, 1940-1980. Lille: PUL, 1990.

CORVIN, Michel. Dramaturgies, langages dramatiques. Paris: Nizet, 1986.

DANAN, Joseph. Le théâtre de la pensée. Paris: Médianes, 1995.

DERRIDA, Jacques. La dissémination. Paris: Seuil, 1972.

KRISTEVA, Julia. Etrangers à nous-mêmes. Paris: Fayard, 1988.

PAVIS, Patrice. Le théâtre au croisement des cultures. Paris: José Corti, 1990. 
PAZ, Octavio. O labirinto da solidão. Trad. de E. Zagury. Rio: Paz e Terra, 1984.

RYNGAERT, Jean-Pierre. Lire le théâtre contemporain. Paris: Dunod, 1993.

SUBIRATS, E. A penúltima visão do paraíso. Trad. de E. Brandão. São Paúlo: Studio Nobel, 2001.

SZONDI, P. Théorie du drame moderne. Traduit de l'allemand par Patrice Pavis, avec la collaboration de Jean et Mayotte Bollack. Lausanne: L'Age d'homme, 1983.

UBERSFELD, Anne. L'école du spectateur. Lire le théâtre II. Ed.S. 1981. 